\title{
KEBIASAAN MAKAN DAN PENGETAHUAN REPRODUKSI REMAJ A PUTRI PESERTA PUSAT INFORMASI DAN KONSELING KESEHATAN REPRODUKSI REMAJ A (PIK-KRR)
}

\author{
(Food Habit and Reproduction Health Knowledge of Female Adolescence Participants in \\ Centre of Information and Counseling of Adolescence Reproduction Health (PIK-KRR))
}

\author{
M. Husni Thamrin ${ }^{1}$, Clara M. Kusharto ${ }^{2}$, dan Budi Setiawan ${ }^{2}$
}

${ }^{1}$ Program Studi Manajemen Ketahahan Pangan (MKP), Sekolah Pascasarjana, IPB.
2 Departemen Gizi Masyarakat, Fakultas Ekologi Manusia (FEMA), IPB
Tel: 0251-8628304/8621258; Fax: 0251-8625846/8622276

\begin{abstract}
The aim of this research was to observe food habit and knowledge of reproduction health of female adolescence participants and non participants of Information Centre and Counseling of Adolescence Reproduction Health (PIK-KRR) at SMU 1 Liwa and SMK 1 Liwa. Reproduction readiness in adolescence is influenced by physical readiness which is reflected from nutrition and health status and mental readiness in the form of adolescence perception about reproduction health. This research used cross sectional design. The site of the research is determined using purposive sampling. The SMU 1 Liwa was choosen because this school has PIK-KRR and most of the graduates continue their study to the higher level of education, and SMKN Liwa Lampung Barat was chosen because this school does not have PIK-KRR yet and most of the graduates do not continue their study. Spearman's Correlation and t-test utilized to know whether there were any difference in each variable in SMU and SMK students. The results of the study show that, SMU female adolescence have better reproduction readiness than SMK female adolescence. Therefore it is important for female adolescence to get correct information about nutrition, and reproduction health through formal or informal ways.
\end{abstract}

Keywords: Female adolescence, food habit, reproduction health

\section{PENDAHULUAN}

Beberapa penelitian pada remaja menunjukkan bahwa 40 persen menderita anemia. Prevalensi anemia pada santri remaja di Leuwiliang Kabupaten Bogor (Permaesih et al., 1998) dan remaja SLTA di Jakarta Timur (Wirawan, 1995) sebesar 44.44\%. Bahkan hasil penelitian Hayatinur (2001) menunjukkan bahwa prevaluasi anemia remaja SMU di Kuningan Jawa Barat lebih tinggi yaitu 61.0\%. Selama ini masalah kesehatan remaja kurang mendapat perhatian serius, karena remaja secara umum tidak mudah terserang penyakit daripada anakanak dan orang tua. Keadaan status gizi remaja pada umumnya dipengaruhi oleh kebiasaan makan yang berakibat pada rendahnya tingkat konsumsi zat gizi. Hal ini disebabkan oleh keterbatasan makanan atau membatasi sendiri makanannya, karena faktor ingin langsing.

Menurut Hurlock (1991) hanya sedikit remaja yang merasa puas dengan tubuhnya, sedangkan ukuran tubuh, usia dan status kesehatan wanita merupakan faktor penting yang mempengaruhi status bayi yang akan dilahir- kannya. Oleh karena itu kesempurnaan dan kematangan fisik khususnya pada remaja putri merupakan salah satu penentu kesiapan remaja menghadapi masa reproduksi yang nantinya menjadi seorang ibu, mengandung, melahirkan, dan mengasuh anak. Kurangnya persiapan mental dan fisik ini menjadi masalah serius yang tidak hanya berdampak pada dirinya akan tetapi juga pada generasi yang dihasilkannya. Suatu penelitian menunjukkan bahwa kehamilan di masa remaja berpotensi melahirkan bayi dengan berat badan lahir rendah (Kusharto \& Florencio, 1994). Kesiapan mental remaja diantaranya terlihat dari persepsi remaja tentang reproduksi. Salah satu faktor yang mempengaruhi persepsi ialah pengetahuan reproduksi. Penelitian menunjukkan hanya sebagian kecil remaja di Indonesia yang memiliki pengetahuan reproduksi yang baik dan mendapat informasi tentang reproduksi dari sumber kompeten (Media, 1995). Berdasarkan Uraian tersebut maka penulis tertarik untuk mengadakan penelitian mengenai kebiasaan makan dan pengetahuan reproduksi remaja putri peserta Pusat Informasi dan Konseling Kesehatan Reproduksi Remaja (PIK-KRR). 
Secara umum penelitian ini bertujuan untuk mempelajari kebiasaan makan dan pengetahuan kesehatan reproduksi remaja putri SMU N Liwa yang aktif sebagai peserta Pusat Informasi dan Konseling Kesehatan Reproduksi Remaja (PIK-KRR) pada SMU Negeri 1 Liwa dan Remaja putri SMK Negeri 1 Liwa yang belum memiliki Pusat Informasi dan Konseling Kesehatan Reproduksi Remaja (PIK-KRR).

\section{METODE PENELITIAN}

\section{Desain, Tempat, dan Waktu Penelitian}

Penelitian ini merupakan penelitian dengan rancangan cross sectional. Penelitian ini dilaksanakan di SMU Negeri dan SMK Negeri Liwa Kabupaten Lampung Barat. Pemilihan SMU Negeri dan SMK Negeri Liwa ini dengan pertimbangan bahwa SMU ini adalah sekolah favorit serta telah memiliki Pusat Informasi dan Konseling Kesehatan Reproduksi Remaja (PIK-KRR). Sedangkan SMK Negeri Liwa berdasarkan pertimbangan belum memiliki Pusat Informasi dan Konseling Kesehatan Reproduksi Remaja (PIK-KRR), waktu penelitian dilakukan pada bulan Nopember sampai dengan Desember 2008.

\section{Penarikan Contoh}

Populasi dalam penelitian ini adalah remaja putri SMA Negeri 1 Liwa dipilih secara sengaja (purposive sampling) yaitu peserta yang aktif dalam kegiatan Pusat Informasi dan Konseling Kesehatan Reproduksi Remaja (PIKKRR) sebanyak 30 orang siswi sedangkan di SMK Negeri 1 Liwa Lampung Barat pengambilan contoh penelitian dilakukan dengan cara klaster yaitu satu kelas sebanyak 30 siswi kelas 2 yang ditentukan oleh pihak sekolah.

\section{Lenis dan Cara Pengumpulan Data}

Data yang dikumpulkan berupa data sekunder dan data primer. Data sekunder meliputi keadaan umum sekolah dan siswa. Data primer yang dikumpulkan adalah meliputi sosial ekonomi keluarga, pendapatan keluarga, pengetahuan gizi, frekuensi makan, perilaku konsumsi, status gizi (berat badan, tinggi badan, dan kadar hemoglobin), status fisiologis, pengetahuan dan persepsi terhadap kesehatan reproduksi. Pengumpulan data primer dilakukan dengan teknik pengisian kuesioner oleh peneliti dengan metode wawancara.

\section{Pengolahan dan Analisis Data}

Sosial ekonomi dan demografi, pendapatan keluarga, pengetahuan gizi, frekuensi makan, perilaku konsumsi, status gizi (berat badan, tinggi badan, dan kadar hemoglobin), status fisiologis, pengetahuan dan persepsi terhadap kesehatan reproduksi. Analisis data dilakukan dengan menggunakan program SPSS, kemudian dianalisa secara deskriptif. Untuk mengetahui hubungan antar variabel digunakan uji korelasi Spearman'n, sedangkan uji beda $t$ digunakan untuk menganalisis perbedaan berbagai variabel kuantatif di SMAN 1 Liwa dengan SMKN 1 Liwa.

\section{HASIL DAN PEMBAHASAN}

\section{Karakteristik Contoh}

Pada umumnya sebagian besar contoh di SMU maupun SMK berumur 16 tahun, dengan persentase 56.7\%. Adapun kisaran umur 14 sampai 17 tahun, dengan rata-rata $15.95 \pm$ 0.54 tahun.

\section{Besar Keluarga}

Besar keluarga di kedua sekolah berkisar antara 3 sampai 7 orang. Secara keseluruhan rata-rata jumlah anggota keluarga contoh termasuk kategori keluarga sedang dengan persentase di SMU $66.7 \%$ dan di SMK 43.3\%. Berdasarkan keluarga contoh dikelompokkan menurut jumlah anggota keluarga dengan kategori keluarga kecil ( $\leq 4$ orang), keluarga sedang ( 5 6 orang) dan keluarga besar ( $>6$ orang). Tidak ada perbedaan yang nyata besar keluarga SMU dan SMK.

\section{Pendidikan Orang Tua}

Tingkat pendidikan orang tua (bapak dan ibu) contoh pada umumnya berpendidikan menengah. Tingkat pendidikan orang tua dikelompokkan menurut lama sekolah, dengan kakategori pendidikan dasar 1 - 6 tahun, menengah 7 - 12 tahun dan tinggi $>12$ tahun. Lama sekolah bapak berkisar 1 sampai 17 tahun, persentase bapak yang berpendidikan perguruan tinggi di SMK (40\%) dan SMK (6.6\%). Berdasarkan pengelompokkan tersebut, maka sebagian besar tingkat pendidikan bapak termasuk kategori pendidikan menengah $53.4 \%$ untuk SMU dan kategori pendidikan dasar dan menengah $46.6 \%$ untuk SMK. Sebagian besar pendidikan ibu responden adalah menengah dengan lama pendidikan berkisar 1 sampai 17 tahun. Secara umum, tingkat pendidikan ibu contoh di 
SMU menengah 60\% dan SMK termasuk kategori pendidikan dasar $66.7 \%$ (Tabel 2).

Tabel 1. Sebaran Contoh SMU dan SMK berdasarkan Besar Keluarga

\begin{tabular}{lcccc}
\hline \multirow{2}{*}{ Besar Keluarga } & \multicolumn{2}{c}{ SMU } & \multicolumn{2}{c}{ SMK } \\
\cline { 2 - 5 } & $\mathbf{n}$ & $\%$ & $\mathbf{n}$ & $\%$ \\
\hline Kecil & 9 & 30.0 & 14 & 46.7 \\
Sedang & 20 & 66.7 & 13 & 43.3 \\
Besar & 1 & 3.3 & 3 & 10.0 \\
\hline Jumlah & 30 & 100.0 & 30 & 100.0 \\
\hline
\end{tabular}

Tabel 2. Sebaran Contoh SMU dan SMK berdasarkan Pendidikan Orang Tua

\begin{tabular}{lcccc}
\hline \multirow{2}{*}{$\begin{array}{c}\text { Pendidikan Orang } \\
\text { Tua }\end{array}$} & \multicolumn{2}{c}{ SMU } & \multicolumn{2}{c}{ SMK } \\
\cline { 2 - 5 } & $\mathbf{n}$ & $\%$ & N & $\%$ \\
\hline Pendidikan Bapak & & & & \\
$\quad$ Dasar & 2 & 6.6 & 14 & 46.7 \\
$\quad$ Menengah & 16 & 53.4 & 14 & 46.7 \\
$\quad$ Tinggi & 12 & 40.0 & 2 & 6.6 \\
\hline Jumlah & 30 & 100.0 & 30 & 100.0 \\
\hline Pendidikan Ibu & & & & \\
$\quad$ Dasar & 4 & 13.3 & 20 & 66.7 \\
$\quad$ Menengah & 18 & 60.0 & 9 & 30.0 \\
$\quad$ Tinggi & 8 & 26.7 & 1 & 3.3 \\
\hline Jumlah & 30 & 100.0 & 30 & 100.0 \\
\hline
\end{tabular}

Terdapat perbedaan nyata $(\mathrm{p}<0.05)$ lama sekolah orang tua contoh di SMU dan SMK. Lama sekolah orang tua di SMU lebih tinggi dari pada SMK.

\section{Pekerjaan Orang Tua}

Pekerjaan orang tua contoh secara umum adalah petani dan pedagang khususnya di SMK, pekerjaan bapak sebanyak $66.6 \%$ sebagai petani dan ibu $70.0 \%$ petani. Meskipun pekerjaan bapak di SMU yang tertinggi sebagai pedagang (46.6\%). Sedangkan ibu contoh di SMU bekerja sebagai pedagang $43.3 \%$. Terdapat perbedaan nyata $(p<0.05)$ pekerjaan bapak contoh di SMU dan SMK, begitu juga terdapat perbedaan yang nyata $(\mathrm{p}<0.05)$ pada pekerjaan ibu di kedua sekolah.

\section{Pendapatan Keluarga}

Pendapatan keluarga contoh per bulan berkisar antara Rp400 000 hingga Rp7 600000 kriteria pendapatan dikelompokkan berdasarkan hasil survey Perlindungan Sosial BPS Lampung Barat tahun 2008 (belum dipublikasikan), adalah $\leq$ Rp800 000/keluarga /bulan adalah miskin, >Rp800 000/keluarga /bulan adalah tidak miskin. Berdasarkan kriteria tersebut yang termasuk pendapatan rendah ( $\leq$ Rp. 800 000), tinggi ( $\geq$ Rp. 800 000) maka terlihat bahwa pendapatan keluarga contoh di SMU 93.3\% adalah tinggi dan 6.7\% rendah, sedang pendapatan keluarga di SMK yang tinggi $36.7 \%$ dan rendah $63.3 \%$ (Tabel 3). Hasil analisis menunjukkan bahwa adanya perbedaan yang nyata $(p<0.05)$ pendapatan keluarga responden di kedua sekolah tersebut. Pendapatan keluarga contoh di SMU lebih tinggi dari pada pendapatan keluarga contoh di SMK.

Tabel 3. Sebaran Contoh SMU dan SMK berdasarkan Pendapatan Keluarga

\begin{tabular}{lcccc}
\hline \multirow{2}{*}{ Pendapatan Keluarga } & \multicolumn{2}{c}{ SMU } & \multicolumn{2}{c}{ SMK } \\
\cline { 2 - 5 } & $\mathbf{n}$ & $\%$ & $\mathbf{n}$ & $\%$ \\
\hline Rendah & 2 & 6.7 & 19 & 63.3 \\
Tinggi & 28 & 93.3 & 11 & 36.7 \\
\hline Jumlah & 30 & 100.0 & 30 & 100.0 \\
\hline
\end{tabular}

Pendapatan keluarga berhubungan secara signifikan dengan pendidikan bapak $(p<0.05)$ dan pendidikan ibu $(p<0.05)$, yang berarti makin lama pendidikan orang tua makin tinggi pendapatan keluarga. Jahari (2000) mengemukakan bahwa tingkat pendapatan merupakan indikator sosial yang dapat mencerminkan keadaan sosial ekonomi seseorang. Pendidikan bapak secara langsung maupun tidak langsung akan menentukan keadaan ekonomi keluarga, sedangkan pendidikan ibu merupakan modal dasar guna memperkuat perekonomian keluarga.

\section{Uang J ajan Contoh}

Uang jajan contoh berkisar antara Rp26 000 sampai Rp300 000 dengan rata-rata Rp100 $267 \pm$ Rp59 812 berdasarkan kriteria uang jajan kategori rendah, sedang dan tinggi diketahui $83 \%$, contoh SMU memiliki uang jajan sedang dan $50 \%$ di SMK memiliki uang jajan rendah lihat Tabel 4.

Tabel 4. Sebaran Contoh SMU dan SMK berdasarkan Uang Jajan

\begin{tabular}{lcccc}
\hline \multirow{2}{*}{ Uang Jajan } & \multicolumn{2}{c}{ SMU } & \multicolumn{2}{c}{ SMK } \\
\cline { 2 - 5 } & $\mathbf{n}$ & $\%$ & $\mathbf{n}$ & $\%$ \\
\hline Rendah & 2 & 6.7 & 15 & 50.0 \\
Sedang & 25 & 83.3 & 14 & 46.7 \\
Tinggi & 3 & 10.0 & 1 & 3.3 \\
\hline Jumlah & 30 & 100.0 & 30 & 100.0 \\
\hline
\end{tabular}


Tidak terdapat perbedaan nyata uang jajan contoh di SMU dengan SMK, SMU memiliki uang jajan lebih tinggi dibanding contoh SMK, hal ini mungkin berkaitan dengan pendapatan keluarga di SMU yang lebih baik dibanding SMK.

\section{Kebiasaan Makan}

Perilaku konsumsi dinilai dari jawaban contoh atas pertanyaan mengenai frekuensi makan (minimal nasi dan lauk pauk), komposisi makanan empat sehat, produk pelangsing, serta makanan pantangan. Sebagian besar contoh memiliki frekuensi makan tiga kali sehari dengan persentase di SMU $63.3 \%$ dan di SMK 76.7\%. Frekuensi makan dua kali sehari atau kurang bisa berdampak negatif bagi kesehatan. Jika dilihat lebih lanjut, maka masih terdapat contoh di SMK yang makan hanya satu kali dalam sehari (6.6\%). Hal ini terjadi karena yang dimaksud makan oleh peneliti adalah makan yang minimal terdiri dari nasi dan lauk pauk. Kebiasaan makan tiga kali sehari atau lebih merupakan kebiasaan makan yang baik, karena dengan frekuensi konsumsi yang makin sering diharapkan akan semakin besar kemungkinan terpenuhinya kebutuhan gizi.

Peluang untuk mencukupi kebutuhan gizi akan lebih besar jika frekuensi makan tiga kali sehari. Persentase contoh yang mengkonsumsi makanan empat sehat (nasi, lauk pauk, sayur dan buah) satu hari sebelum penggambilan data di SMU sebanyak $90 \%$ dan di SMK sebanyak $63.3 \%$. Persentase contoh yang mengkonsumsi makanan empat sehat kurang dari tujuh kali dalam seminggu di SMU sebanyak $56.6 \%$ dan di SMK sebanyak $100 \%$.

Contoh di SMU yang mengkonsumsi pelangsing hanya 1 orang (3.3\%) sedangkan di SMK tidak ada yang mengkonsumsi pelangsing. Persentase contoh yang memiliki makanan pantangan di SMU sebanyak $20 \%$ dan di SMK sebanyak $6.7 \%$. Jenis makanan yang dipantang sebagian besar adalah udang dengan alasan dapat menyebabkan alergi. Seharusnya udang tidak menjadi makanan yang dipantang karena menurut udang dan telur merupakan sumber zat besi heme yang lebih mudah di absorpsi dan penyerapannya tidak tergantung pada jenis kandungan makanan lain. Kebiasaan makan contoh yang dinilai dari skor gabungan jawaban pertanyaan tentang frekuensi makan 2 kali atau lebih dalam satu hari, komposisi makan 4 sehat, frekuensi komposisi makan 4 sehat, penggunaan produk pelangsing, makanan pantangan pada contoh SMU sebanyak 63.3\% dan SMK 16.7\% dikategorikan baik, sedangkan yang kurang sejumlah $83.3 \%$ contoh di SMK dan di SMU 36.7\% (Tabel 5).

Tabel 5. Sebaran Contoh SMU dan SMK menurut Kebiasaan Makan

\begin{tabular}{lcccc}
\hline \multirow{2}{*}{ Perilaku Konsumsi } & \multicolumn{2}{c}{ SMU } & \multicolumn{2}{c}{ SMK } \\
\cline { 2 - 5 } & $\mathbf{n}$ & $\%$ & $\mathbf{n}$ & $\%$ \\
\hline Baik & 19 & 63.3 & 5 & 16.7 \\
Kurang & 11 & 36.7 & 25 & 83.3 \\
\hline Jumlah & 30 & 100.0 & 30 & 100.0 \\
\hline
\end{tabular}

Jenis pangan sumber karbohidrat yang banyak dikonsumsi contoh di SMU ialah nasi dengan frekuensi 61-90 kali/bulan (63.3\%), roti dengan frekuensi $16-30 \mathrm{kali} /$ bulan (33.3\%), mie dengan frekuensi 1-7 kali/bulan (30\%), sedangkan di SMK, contoh yang mengonsumsi nasi dengan frekuensi 61-90 kali/bulan (90\%), roti dengan frekuensi 8-15 kali/bulan (10\%), mie dengan frekuensi 8-51 kali/bulan (40\%).

\section{Pengetahun Gizi dan Kesehatan}

Pengetahuan gizi dan kesehatan contoh yang dinilai terdiri atas 3 aspek, yaitu: 1) jenis, fungsi dan sumber zat gizi; 2) kebutuhan dan status gizi; dan 3) Masalah gizi remaja. Penilaian pengetahuan gizi dan kesehatan didasarkan pada jumlah skor kemudian dikelompokkan dengan kategori pengetahuan gizi baik ( $>80 \%$ benar), sedang $(60 \%-80 \%)$ dan kurang $(<60 \%$ benar).

Penilaian pengetahuan gizi masingmasing aspek menunjukkan bahwa aspek jenis, fungsi dan sumber zat gizi, aspek kebutuhan serta status gizi. Sebagian besar contoh adalah kategori pengetahuan gizi kurang. Pada aspek jenis, fungsi dan sumber zat gizi terdapat $70 \%$ contoh di SMU dengan pengetahuan gizi sedang dan $70 \%$ contoh di SMK dengan pengetahuan gizi kurang.

Pengetahuan gizi contoh termasuk dalam kategori rendah, persentse tertinggi di SMK kategori pengetahuan gizi kurang sebanyak $76.7 \%$ dan SMU 60\% (Tabel 6). Pengetahuan gizi dan kesehatan contoh di SMU tidak ada perbedaan secara nyata $(p>0.05)$ dibandingkan dengan responden SMK. Pengujian menggunakan korelasi Spearman's memperlihatkan adanya hubungan positif yang signifikan antara pengetahuan gizi dengan pendidikan orang tua $(p<0.05)$ serta pendapatan keluarga $(p<0.05)$. Hal ini berarti bahwa makin tinggi tingkat pendidikan orang tua dan pendapatan keluarga, maka pengetahuan gizi dan kesehatan semakin baik. 
Tabel 6. Sebaran Contoh SMU dan SMK berdasarkan Pengetahuan Gizi dan Kesehatan

\begin{tabular}{lcccc}
\hline \multirow{2}{*}{$\begin{array}{c}\text { Pengetahuan Gizi } \\
\text { dan Kesehatan }\end{array}$} & \multicolumn{2}{c}{ SMU } & \multicolumn{2}{c}{ SMK } \\
\cline { 2 - 5 } & $\mathbf{n}$ & $\%$ & $\mathbf{N}$ & $\%$ \\
\hline Kurang & 18 & 60.0 & 23 & 76.7 \\
Sedang & 12 & 40.0 & 7 & 23.3 \\
Baik & 0 & 0.0 & 0 & 0.0 \\
\hline Jumlah & 30 & 100.0 & 30 & 100.0 \\
\hline
\end{tabular}

\section{Status Gizi}

\section{Indeks Massa Tubuh}

Status gizi contoh dinilai berdasarkan Indeks Massa Tubuh (IMT), klasifikasi status gizi tersebut dikatakan normal jika memiliki nilai IMT berkisar 18.5 hingga 24.9 (Depkes, 1996). Hasil penilaian status gizi contoh menunjukkan nilai IMT yang cukup beragam dan berkisar antara 14.4 sampai 28.6 yang berarti status gizi contoh berkisar dari status gizi kurang hingga status gizi baik. Dari nilai rata-rata nilai IMT $19.68 \pm 2.37$. Persentase nilai IMT contoh di SMU dan SMK yang terbesar adalah normal $66.6 \%$ dan $83.3 \%$, kemudian kurus (kurang) 30\% dan $16.7 \%$ dan gemuk $1.4 \%$ di SMA yang dapat dilihat pada (Gambar 2). Status gizi contoh SMU dan SMK tidak berbeda secara nyata.

\section{Status Besi}

Status besi contoh dinilai dari hasil pengukuran hemoglobin $(\mathrm{Hb})$ dalam darah. Kadar $\mathrm{Hb}$ contoh berkisar antara 8.8 sampai 12 $\mathrm{g} / \mathrm{dl}$ dan tidak anemia jika kadar $\mathrm{Hb} \geq 12 \mathrm{~g} / \mathrm{dl}$, sedangkan yang anemia dikelompokkan anemia berat $\mathrm{Hb}<10 \mathrm{~g} / \mathrm{dl}$, anemia sedang $\mathrm{Hb} \geq 10-12$ $\mathrm{g} / \mathrm{dl}$, berdasarkan kriteria tersebut diketahui yang berstatus tidak anemia sebanyak (3.3\%) contoh SMU, berstatus anemia sedang SMU $66.7 \%$ dan di SMK $76.7 \%$ sedangkan berstatus anemia berat $30 \%$ di SMU dan $33.3 \%$ di SMK (Gambar 3). Tidak terdapat perbedaan secara nyata status besi (hemoglobin) contoh di SMU dan SMK.

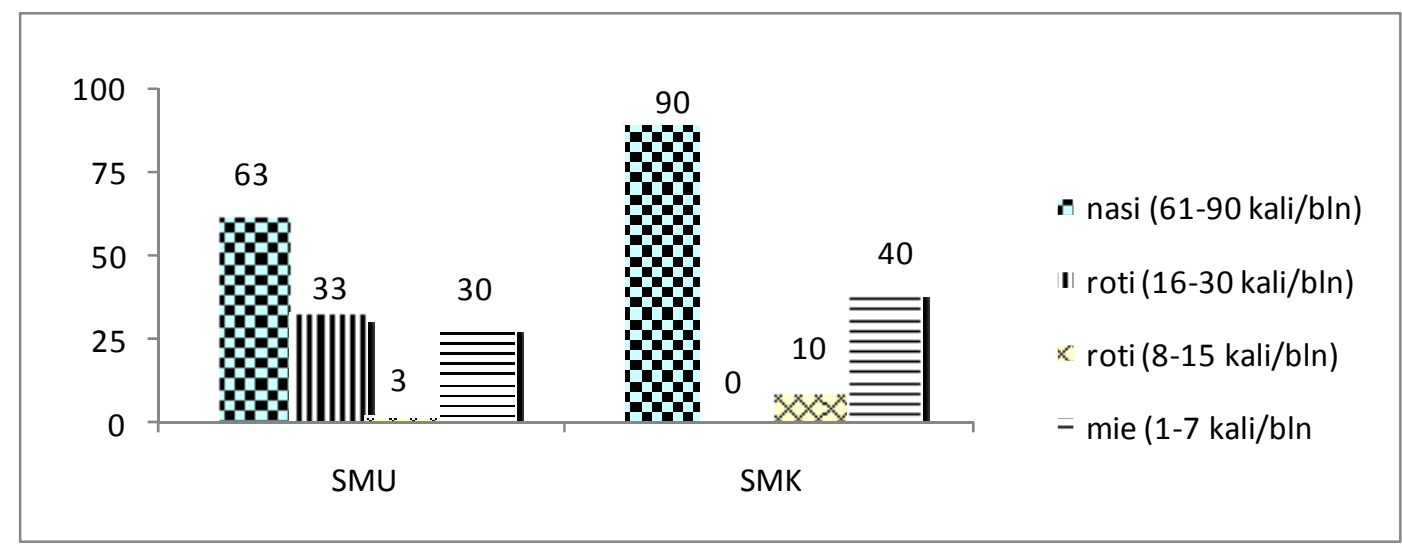

Gambar 1. Sebaran Contoh SMU dan SMK menurut Jenis Pangan Sumber Karbohidrat yang Banyak Dikonsumsi

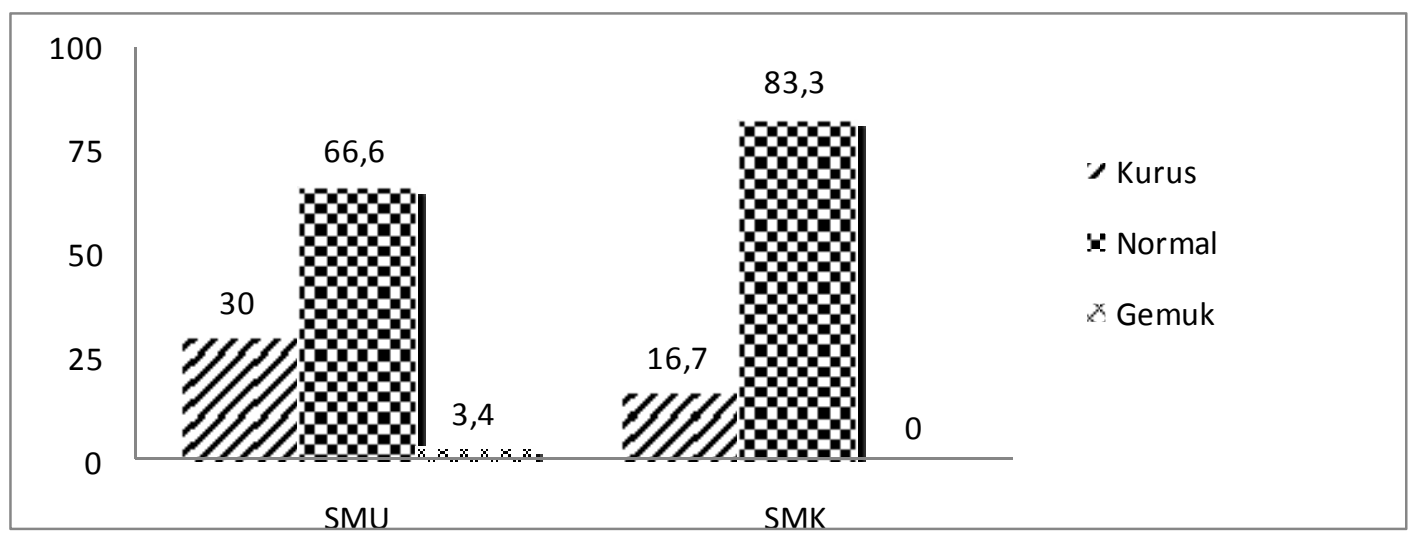

Gambar 2. Persentase Sebaran Contoh SMU dan SMK menurut Indeks Massa Tubuh 


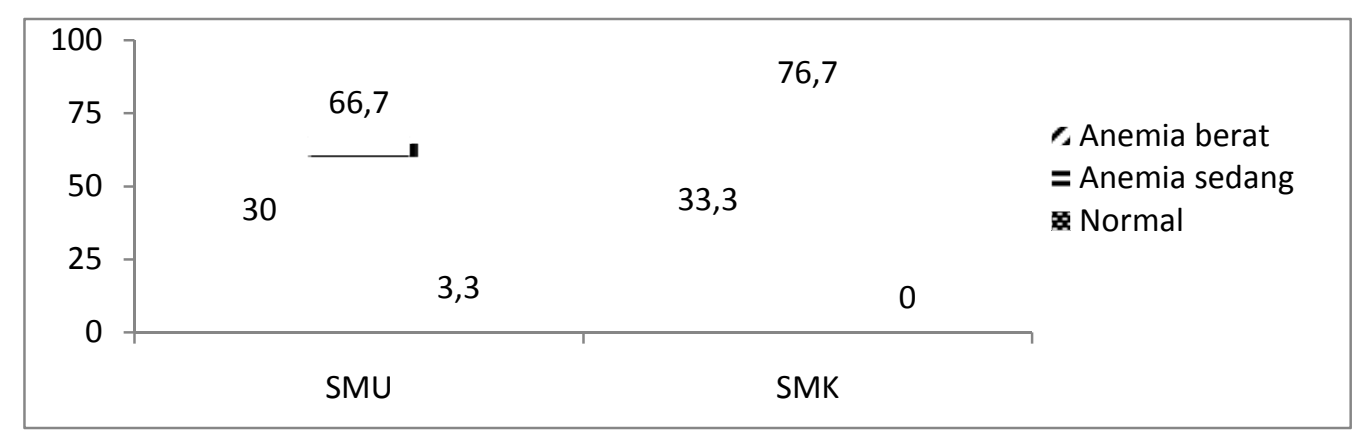

Gambar 3. Sebaran Contoh SMU dan SMK menurut Status Besi

\section{Pengetahuan Reproduksi}

Pengetahuan reproduksi responden dikelompokkan menjadi kategori baik (>80\% benar), sedang $(60 \%-80 \%$ benar) dan kurang $(<60 \%$ benar). Secara umum diketahui bahwa sebagian besar contoh memiliki pengetahuan reproduksi baik, yaitu sebanyak $86.7 \%$ di SMU dan 43.3\% di SMK, contoh yang memiliki pengetahuan reproduksi sedang $13.3 \%$ di SMU di SMK $30 \%$ dan hanya responden di SMK yang memiliki pengetahuan reproduksi kurang 26.7\% (Tabel 7). Uji beda $t$ menunjukkan bahwa pengetahuan reproduksi di SMU lebih baik dibandingkan dengan SMK $(p<0,05)$. Hasil penelitian ini sedikit berbeda dengan penelitian sebelumnya di Bangkinang, Kabupaten Kampar, Propinsi Riau, yaitu pengetahuan reproduksi remaja yang masih kurang sebanyak 91.6\%, sedang sebanyak 3.3\% serta baik sebanyak $5.5 \%$ (Anita, 2007). Tingginya persentase responden dengan pengetahuan reproduksi baik ini menunjukkan keberhasilan penyampaian informasi yang dilakukan oleh Pusat Informasi dan konseling kesehatan Reproduksi Remaja yang ada di SMU.

Tabel 7. Sebaran Contoh SMU dan SMK berdasarkan Pengetahuan Reproduksi

\begin{tabular}{lcccc}
\hline \multicolumn{1}{c}{$\begin{array}{c}\text { Pengetahuan } \\
\text { Reproduksi }\end{array}$} & \multicolumn{2}{c}{ SMU } & \multicolumn{2}{c}{ SMK } \\
\cline { 2 - 5 } \multicolumn{1}{c}{} & $\mathbf{n}$ & $\%$ & $\mathbf{N}$ & $\%$ \\
\hline Kurang & 0 & 0.0 & 8 & 26.7 \\
Sedang & 4 & 13.3 & 9 & 30.0 \\
Baik & 26 & 86.7 & 13 & 43.3 \\
\hline Jumlah & 30 & 100.0 & 30 & 100.0 \\
\hline
\end{tabular}

\section{Persepsi terhadap Kesehatan Reproduksi}

Persepsi kesehatan reproduksi merupakan pandangan atau pemahaman terhadap segala aspek yang mendukung terwujudnya reproduksi sehat. Aspek-aspek yang dinilai meliputi aspek kemampuan (usia reproduksi dan perawatan alat reproduksi), aspek keberhasilan (status gizi dan konsumsi, serta hubungan seksual), dan aspek keamanan (alat kontrasepai, aborsi, dan penyakit menular seksual). Hasil penilaian persepsi contoh terhadap kesehatan reproduksi umumnya sudah cukup baik (76.7\%). Kriteria persepsi dikelompokkan menjadi persepsi baik $(\geq 60 \%)$ dan persepsi kurang $(<60 \%)$, dengan nilai tengah atau median $60 \%$. Berdasarkan kriteria tersebut, di SMU 100\% memiliki persepsi kesehatan reproduksi baik. Sebaliknya di SMK jumlah yang memiliki persepsi terhadap kesehatan reproduksi yang kurang $46.7 \%$ dan yang memiliki persepsi baik 53.3\%. Persepsi terhadap kesehatan reproduksi contoh SMU secara nyata $(p<0.05)$ lebih baik dibanding responden SMK (Tabel 8).

Hasil uji korelasi Spearman's memperlihatkan bahwa terdapat hubungan yang signifikan antara persepsi dengan pendidikan bapak $(p<0.05)$, pendidikan ibu $p<0.05)$ serta pengetahuan reproduksi $(p<0.05)$.

Tabel 8. Sebaran Contoh SMU dan SMK Persepsi terhadap Kesehatan Reproduksi

\begin{tabular}{ccccc}
\hline \multirow{2}{*}{$\begin{array}{c}\text { Persepsi Terhadap } \\
\text { Kesehatan Reproduksi }\end{array}$} & \multicolumn{2}{c}{ SMU } & \multicolumn{2}{c}{ SMK } \\
\cline { 2 - 6 } & $\mathbf{n}$ & $\%$ & $\mathbf{n}$ & $\%$ \\
\hline Persepsi Terhadap Kesehatan Reproduksi & & \\
Kurang & 0 & 0.0 & 14 & 46.7 \\
Baik & 30 & 100.0 & 16 & 53.3 \\
\hline Jumlah & 30 & 100.0 & 30 & 100.0 \\
\hline
\end{tabular}

\section{Status Fisiologis}

Masa remaja merupakan masa pertumbuhan anak menjadi dewasa. Pada masa remaja akan terjadi perubahan yang menyangkut aspek fisiologis yang ditandai dengan adanya menstruasi. Usia pertama kali menstruasi contoh di SMU pada usia 11 tahun (10\%), usia 12 tahun (36.6\%), usia 13 tahun (33.3\%), usia 14 tahun (20\%), Sedangkan contoh SMK usia 11 tahun (6.6\%), usia 12 tahun (30\%), usia 13 tahun (40\%) dan usia 14 tahun (23.3\%). Usia pertama 
menstruasi dikelompokkan menjadi tiga yaitu lebih awal (11 tahun), normal (11-15 tahun), dan lambat (>15 tahun). Sebagian besar contoh di SMA (90\%) dan di SMK (93.3\%) mendapatkan menstruasi pertama kali pada usia 1115 tahun yang termasuk dikategorikan normal. Menurut Jones (1997) rata-rata seorang gadis mengalami menstruasi pertama pada usia 13 tahun dan paling lambat pada usia 16 tahun. Tidak terdapat beda yang nyata antara usia menstruasi contoh SMU dan SMK. Berdasarkan uji korelasi Spearman's tidak terdapat hubungan antara usia pertama menstruasi dengan status gizi dilihat dari indek massa tubuh contoh SMU dengan SMK.

\section{Kesiapan Reproduksi}

Kesiapan reproduksi contoh dinilai berdasarkan status gizi (IMT dan $\mathrm{Hb}$ ) dan persepsi remaja terhadap kesehatan reproduksi. Status gizi digunakan sebagai indikator kesiapan fisik remaja, sedangkan kesiapan mental remaja diukur dari persepsi terhadap kesehatan reproduksi. Kesiapan reproduksi dikategorikan menjadi baik, sedang dan kurang. Data yang diperoleh menunjukkan persentase terbesar yaitu $66.7 \%$ contoh SMU dan $50 \%$ responden SMK memiliki kesiapan reproduksi sedang, sedangkan contoh SMU 33.3\% dan SMK $50 \%$ memiliki kesiapan reproduksi kurang (Gambar 4).

Kesiapan reproduksi yang baik dimiliki oleh contoh dengan status gizi baik (IMT normal dan status besi tidak anemia). Hal ini sesuai pernyataan Jones (1997) bahwa terjadinya komplikasi selama kehamilan dan persalinan semakin sedikit pada ibu yang memiliki pengetahuan cukup tentang kehamilan atau reproduksi, memiliki tinggi lebih dari $155 \mathrm{~cm}$, tidak terlalu kurus dan tidak terlalu gemuk.

Persepsi yang kurang baik berindikasi semakin kurangnya kesiapan reproduksi remaja. Hasil analisis statistik mengenai status gizi dengan persepsi terhadap kesehatan reproduksi tidak memperlihatkan hubungan yang signifikan. Pusat Informasi dan Konseling Ke- sehatan Reproduksi Remaja (PIK-KRR) yang ada di SMUN menyebabkan akses informasi yang tepat mengenai gizi dan reproduksi lebih mudah diperoleh dari pada responden SMK. Berdasarkan hasil tersebut dapat dikatakan remaja putri SMK yang telah disiapkan untuk segera mandiri dan memiliki kencendrungan segara menikah terbukti tidak lebih siap dalam reproduksi dibanding remaja putri SMU yang lebih berorientasi untuk menempuh pendidikan lebih tinggi.

\section{KESIMPULAN}

Karakteristik sosial ekonomi (pendidikan orang tua, pendapatan keluarga) siswi SMU Negeri Liwa peserta Pusat Informasi dan Konseling Kesehatan Reproduksi Remaja (PIKKRR) secara nyata $(p<0.05)$ lebih baik dibanding kan dengan siswi SMK Negeri Liwa.

Kebiasaan makan siswi SMU Negeri secara nyata $(p<0.05)$ lebih baik dibandingkan dengan siswi SMK Negeri Liwa.

Baik siswi SMU Negeri Liwa maupun SMK Negeri Liwa Pengetahuan gizi termasuk kategori Kurang. Status gizi (IMT) secara umum termasuk normal $(70.5 \%)$ dan prevalensi anemia tinggi (98.3\%).

Siswi SMU Negeri Liwa memiliki pengetahuan kesehatan reproduksi secara nyata $(p<0.05)$ lebih baik dari SMK Negeri Liwa.

Persepsi terhadap kesehatan reproduksi siswi SMU Negeri secara nyata $(p<0.05)$ lebih baik dibandingkan SMK Negeri Liwa dan berhubungan sangat nyata $(p<0.05)$ dengan pendidikan orang tua maupun dengan pengetahuan kesehatan reproduksi $(\mathrm{p}<0.05)$.

Kesiapan reproduksi siswi SMU Negeri secara nyata $(p<0.05)$ lebih baik dari SMK Negeri Liwa dan berhubungan nyata $(p<0.05)$ dengan pengetahuan gizi, namun tidak terdapat hubungan yang nyata antara status gizi dengan persepsi terhadap kesehatan reproduksi.

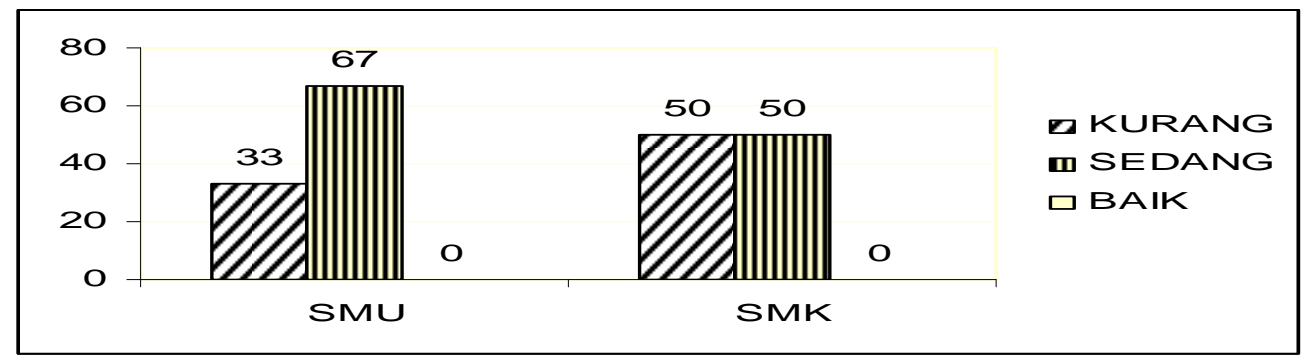

Gambar 4. Sebaran Contoh SMU dan SMK berdasarkan Kesiapan Reproduksi 


\section{DAFTAR PUSTAKA}

Anita R. 2007. Pola Konsumsi Pangan, Status Gizi dan Pengetahuan Reproduksi Remaja Putri. Tesis Magister, Fakultas Pasca sarjana IPB, Bogor.

Hurlock EB. 1991. Psikologi Perkembangan, Suatu Pendekatan Sepanjang Rentang Kehidupan. Edisi Kelima. Erlangga, Jakarta.

Kusharto CM \& Florencio CA. 1994. Effect of Age at Marriage on Nutritional Status of Mother and Child and Their Biological Characteristics. Dalam: Indonesia Nutrition Association. Proceeding of the First Asian Conference on Dietetics; Jakarta, 2-5 Oktober. Indonesia Nutrition Association, Jakarta. P : 104-106.

Media Y. 1995. Pengetahuan, Sikap dan Prilaku Remaja Tentang Kesehatan Reproduksi. Media Penelitian dan Pengembangan Kesehatan.
Jones DL. 1997. Setiap Wanita. Penerbit Delapratasa, Jakarta.

Hayatinur E. 2001. Prevalensi Anemia dan Perilaku Makan Remaja Putri di SMU 2 Kuningan Kabupaten Kuningan. Skripsi Sarjana, Jurusan Gizi Masyarakat dan Sumber Daya Keluarga, Fakultas Pertanian, IPB, Bogor.

Jahari AB. 2000. Status Gizi Balita di Indonesia Sebelum dan Selama Krisis (Analisis Data Antropometri SUSENAS 1985 sid 1998). Prosiding widyakarya Nasional Pangan dan Gizi VIL. LIPI, Jakarta.

Wirawan R. 1995. Diagnosis Anemia. Majalah Kedokteran 45(12) hlm 43-50.

Permaesih. 1990. Status Gizi Kelompok Pekerja dan Wanita Remaja. Puslitbang Gizi, Bogor. 